\title{
Contaminación por aguas residuales e indicadores de calidad en la reserva nacional 'Lago Junín', Perú
}

\author{
Leoncio Filiberto Cusiche Pérez ${ }^{1}$ \\ Gloria Amparo Miranda Zambrano ${ }^{2 \S}$
}

${ }^{1}$ Universidad Nacional del Centro del Perú. Av. Mariscal Castilla núm. 3909, El Tambo, Huancayo, Perú. Tel. 064 481060. (leoncio644@ hotmail.com). ${ }^{2}$ Universidad de Guanajuato. Javier Barros Sierra 201, Ejido Santa Ma. del Refugio, Celaya, Guanajuato, México. CP. 38040. Tel. 4421371659.

${ }^{\S}$ Autora para correspondencia: mirandazambrano.gloria@yahoo.com.mx.

\section{Resumen}

En el Perú, la contaminación del agua es uno de los mayores problemas ambientales (Custodio y Chávez, 2017), considerando que la fragilidad de los ecosistemas acuáticos impacta destructivamente a la biodiversidad, cuya biota local concentra comunidades ecológicas únicas. Dicho problema se estudió en el lago Junín, donde la presión antropogénica desconoce la conservación y la sustentabilidad del medio ambiente y la biodiversidad. Prima la satisfacción de las necesidades productivas (pecuaria, agrícola y extractiva) y la presión de empresas e instituciones (minería, hospitales, mercados) quienes vierten sus aguas residuales al lago afectando los hábitats. El objetivo de la presente investigación fue escudriñar el impacto del agua residual a esos ecosistemas y su zona de influencia señalando el nivel de calidad de agua. El tipo de investigación que abarcó de 2015 a 2017 es descriptivo, de diseño evolutivo contemporáneo longitudinal. Se estableció dos épocas de muestreo (lluvia y estiaje) para el análisis físicoquímico y bacteriológico de agua. Los resultados arrojan que la demanda bioquímica de oxígeno (DBO5) superan los límites máximos permisibles y en época de estiaje son aguas de mala calidad. Las descargas de aguas residuales es factor contaminante con peligro de toxicidad para la vida acuática del lago, afectando especies de flora y fauna endémica y en general todo el ecosistema.

Palabras claves: amenaza lacustre, contaminantes químicos, Lago Junín, Perú.

Recibido: julio de 2019

Aceptado: agosto de 2019 
El 72\% de los lagos y humedales del mundo están contaminados por vertidos urbanos e industriales, provocando más de la mitad de las enfermedades infecciosas conocidas (Trabajos de Ciencias Naturales, 2013). En algunos países, los lagos y ríos se han transformado en receptáculos de una inmensa variedad de desechos, aguas negras domésticas, afluentes industriales tóxicos y sustancias químicas de actividades agrícolas y lixiviadas hacia las aguas de superficie y freáticas (Agudelo, 2005). La construcción de presas que provocan alteraciones en el medio acuático, y las explotaciones mineras que vierten compuestos contaminantes, sobre todo metales, están deteriorando la biodiversidad acuática lacustre.

Es el caso del lago Junín o Chinchaicocha, contexto donde incursionó la investigación (periodo 2015 a 2017), que integra una extensión promedio de $470 \mathrm{~km}^{2}$ de espejo de agua, ubicado a 4080 msnm dentro de la Reserva Nacional de Junín (Figura 1). Su profundidad media varía entre 8 a 12 $m$ en las zonas centrales del lago, recibiendo aportes de manantiales e infiltraciones que descienden de la cordillera oriental y occidental del río San Juan y de otros ríos menores.

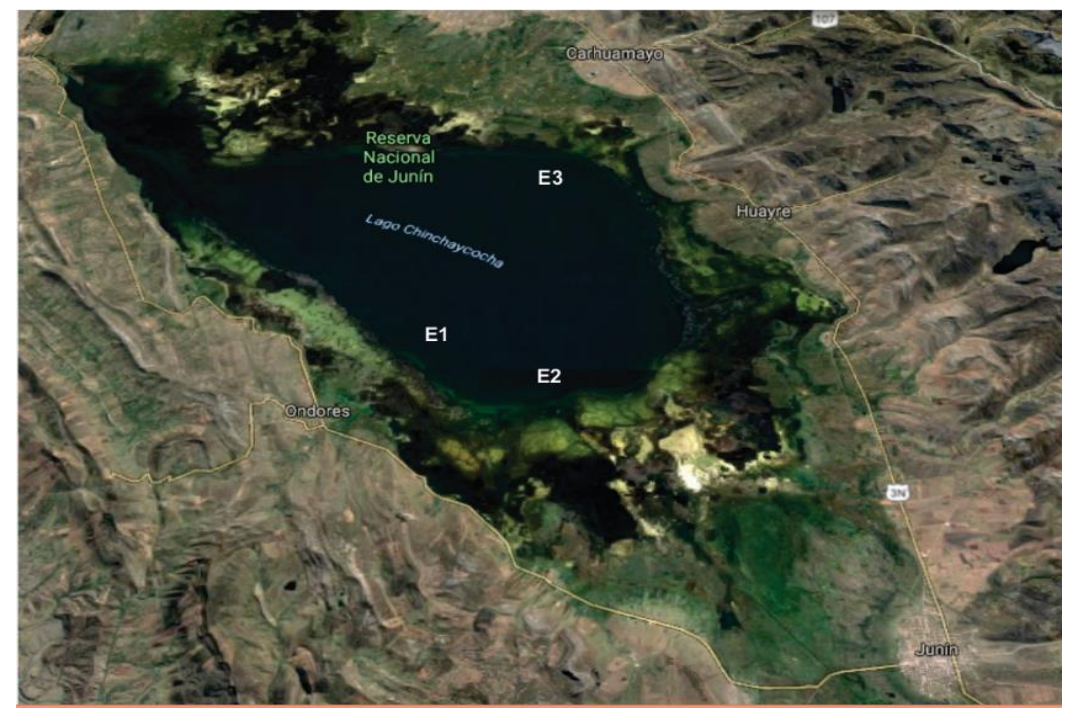

Figura 1. Mapa del 'Lago Junín’ estaciones de muestreo. Fuente: Centro Nacional de estudios espaciales (CNES, 2019).

El paisaje oferta abundantes organismos hidrobiológicos conformados por flora y fauna silvestre, que forman parte de las cadenas tróficas de la vida endémica. La biodiversidad biológica está en correspondencia a la ubicación en zonas inundables y asociaciones de plantas hidrofitas (Plan Maestro RNJ, 2012). Entre las especies que destacan están: el zambullidor de Junín (podiceps taczanowskii), el cóndor andino (vultur gryphus), la gallineta negra (laterallus tuerosii), el halcón peregrino (falco peregrinus) y la gallareta gigante (fulica gigantea).

En mamíferos el zorro andino (psedalupex culpaeus), el zorrino (conepatus chinga), la comadreja (mustela frenata), el gato montés (oncifelis colocolo), el puma (puma concolor), la vicuña (vicugna vicugna), la vizcacha (lagidium peruanum) y el cuy (cavia tschudii). En anfibios y reptiles están el sapo (bufo spinulosus) especie anfibio anuro nocturno, sapo (gastrotheca), sapo (pleuroderma marmorata). De todos ellos, destaca como símbolo del lago, la 'rana Junín' (batrachophrynus macrostomus) quien mide medio metro de largo. 
Entre los tipos de cobertura vegetal más frecuentes están los pajonales, césped de puna, bofedales, oconales y totorales. Según el Plan Maestro RNJ (2012) 'la zona superficial de orilla se evidencia algas verdes (chlorophyta) con 20 especies que representan el 37\% de individuos, las deatomeas presentan $47 \%$ de individuos y las algas azul-verdes contribuyen con $15 \%$, los bentos la presencia de micro invertebrados Ostracoda del orden Podocopa, encarnan 90\% con 6\% de organismos de invertebrados no determinados'. El paisaje presenta un escenario de oferta ambiental viva, en la cual por cientos de generaciones es sustento de comunidades campesinas circundantes.

Sin embargo, esta oferta ambiental amplia y compleja, hace dos décadas está en peligro de extinción, debido a la contaminación del lago y su ámbito de influencia. La responsabilidad de tal impacto se atribuye a las aguas residuales que llegan de los pueblos de Óndores $\left(256 \mathrm{~L} \mathrm{~h}^{-1}\right.$ proveniente de $40 \%$ de la población), Junín (580 $\mathrm{L} \mathrm{h}^{-1}$ representa $85 \%$ de la población), Carhuamayo (184 $\mathrm{L} \mathrm{h}^{-1}$ de $45 \%$ de la población), Ninacaca y Vicco. El agua y alimentos de la zona, al ser consumidos por animales y plantas, evidencian disminución de su población.

El Plan Maestro de la Reserva Nacional de Junín (2012) manifiesta que 'en la RNJ, había 368 especies de plantas y 98 especies de aves y en 1998, según Chauca solamente había 26 especies de vegetales y 36 de aves'. Asimismo, se puede relacionar la fragilidad de la fauna con la destrucción parcial de los hábitats. El Plan Maestro de la Reserva Nacional de Junín (2012) 'comprobó por estudios histológicos, que la rana es afectada por la intoxicación por cobre y el zambullidor tiene problemas por desaparición de su principal alimento las orestias (chalhua) también intoxicado por cobre y zinc'.

Los vertimientos al lago de aguas contaminadas resumen residuos de sulfato de cobre, zinc, ácidos sulfúricos, nítrico y cal, entre otros componentes, siendo las compañías mineras 'Activos Mineros', 'Aurifera Aurex', 'Volcán’ y el 'El Brocal' '(...) quienes tienen participación sobre las afectaciones por contaminación minera y pasivos ambientales' (Chamoro y Medrano, 2010. '(...) el efluente de la Cía. Aurex, presenta alto riesgo en la calidad de agua, encontrándose cobre, plomo y zinc por encima de los límites máximos permisibles normado por el Ministerio de Energía y Minas' (Carrera, 2011).

Grandes cantidades de relaves mineros durante décadas vienen llegando al lago; a través, de la escorrentía de las aguas de lluvias del río San Juan con un impacto altamente tóxico. Los parámetros analizados de los metales de plomo $\left(0.8 \mathrm{mg} \mathrm{L}^{-1}\right)$ y zinc $\left(9.04 \mathrm{mg} \mathrm{L}^{-1}\right)$ exceden los límites máximos permisibles establecido por el Ministerio de Energía y Minas y también los estándares de calidad ambiental del Ministerio del Ambiente-MINAM (Carrera, 2011).

Empeora el panorama contaminante, otros actores y externalidades. Según el Plan Maestro RNJ (2012), el humedal, 'está en proceso de eutrofización, debido a la contaminación de hospitales, hoteles, empresas de lácteos, microempresas de panificación, rastros y la pequeña industria de la maca (Lepidium meyenii Walpers)'. Asimismo, el sobrepastoreo de ganado vacuno y ovino, la explotación de los pastos, la caza y pesca ilegal (Chamorro y Medrano, 2010) y ahora la presencia de un turismo incipiente (Óndores, Uco y Pari).

Entonces, el deterioro de la biodiversidad reflejado en la contaminación de las aguas y afectación de hábitats es ocasionado especialmente por fuente antropogénica. Según INRENA (2000) disminuye la cantidad de oxígeno disuelto, acrecentando la concentración de fósforo provocando 
su eutrofización. Flusche et al. (2005) manifiesta que aumenta la concentración de compuestos químicos y el riesgo para la subsistencia de la biodiversidad acuática. Según, Manahan (2007) 'las aguas residuales de fuentes domésticas, comerciales, de procesado o procesamiento de alimentos e industriales, contienen una amplia variedad de contaminantes, incluyendo a los contaminantes orgánicos' (grasa, sangre, suero de leche y detergentes).

Química y biológicamente contiene gran cantidad de materia orgánica y microorganismos respectivamente, lo cual es caldo de cultivo para enfermedades tanto en humanos como animales. Naquira (2010) sostiene que la fasciolosis es una zoonosis parasitaria causada por el estado adulto del platelminto trematodo Fasciola hepática. Marcelo (2018) evidencia que en la zona hay presencia de problemas digestivos como diarreas, parasitosis intestinal y enfermedades dermatológicas.

La elevada demanda de oxígeno de las aguas residuales, al ser vertidas al medio acuático agota el oxígeno disuelto (Doménech, 2014). En tal sentido, 'algunos contaminantes particularmente las sustancias que demandan oxígeno' (Manahan, 2007) para degradar materiales orgánicos, aceite, grasa y sólidos, interfieren la entrada del $\mathrm{O}_{2}$ hacia el seno del agua y la salida del $\mathrm{CO}_{2}$ y contaminantes inorgánicos muy tóxicos en concentraciones que excedan los estándares de calidad para aguas superficiales destinadas para recreación. Están el fósforo, arsénico y cadmio que son de difícil remoción incluso en las plantas de tratamiento especializado. Completa el panorama, la degradación del suelo, la disminución de la superficie de pastos naturales y la contaminación de la mayoría de las áreas periféricas.

Existen normas sanitarias y alternativas específicas para garantizar los estándares la calidad de agua para lagos y lagunas. Según español (2016), 'la calidad de agua se entiende por su función ambiental potencial, existiendo legislaciones específicas que determinan los umbrales críticos, medios y mínimos de concentraciones admisibles por tipo de contaminante en el agua'. Las empresas mineras circundantes al lago informan el cumplimiento del Programa de Adecuación y Manejo Ambiental (PAMA) para la reducción de impactos, pero no disminuye la contaminación.

De acuerdo al Ministerio del Ambiente (MINAM, 2015), las plantas de tratamiento (pozas de oxidación) de aguas residuales domésticas (PTAR) de las municipalidades en el ámbito del lago, se encuentran colapsadas, sin mantenimiento técnico y presentan un color gris con diversas materias flotantes. Existe el Plan de Manejo de Gestión Sostenible Chinchaycocha 2017-2021, aún sin resultados. Por su parte, la 'Autoridad Administrativa del Agua Mantaro' (2017) ha identificado puntos de vertimientos de aguas residuales directas al lago sin previo tratamiento.

Planteada la compleja problemática, el objetivo que orientó la investigación fue escudriñar el impacto del agua residual a esos ecosistemas y su zona de influencia, señalando el nivel de calidad de agua. Como hipótesis se afirma que el impacto del agua residual en los mencionados ecosistemas del lago y su zona de influencia viene afectando los hábitats con alto nivel de contaminación de fósforo y cloro con problemas de extinción de animales como la rana gigante de Junín. Se analizó desde un enfoque holístico y la revisión precedente con proyección hacia el futuro inmediato.

El propósito de la investigación es determinar los niveles de contaminación del lago mediante análisis fisicoquímico (fosfatos, nitratos, cloruros, dureza cálcica, sólidos disueltos, turbidez, potencial de hidrógeno y conductividad eléctrica), la determinación de indicadores de 
contaminación bioquímica y química (oxígeno disuelto, demanda química y demanda bioquímica), el análisis bacteriológico (coliformes totales y Echerichia coli) por último, determinar la calidad de agua del lago.

Para obtener información integrada sobre la calidad de las aguas, se utiliza el índice de calidad de aguas (ICA), herramienta que sintetiza la información proporcionada por cantidad de parámetros en una expresión sencilla, para generar un valor numérico que permita evaluar la calidad del agua de un sistema (Alarcón y Ñique, 2016). Para Carrillo y Villalobos (2011) 'el ICA el valor del análisis arrojado puede ser el representativo e indicativo del nivel de contaminación'. Por medio del ICA se puede realizar un análisis general de la calidad del agua en diferentes niveles y determinar la vulnerabilidad del cuerpo frente a amenazas potenciales (Soni y Thomas, 2014).

De no revertirse la contaminación, la biodiversidad del lago y la comunidad circundante enfrentarán una situación de alto riesgo en las próximas dos o tres décadas.

Los materiales utilizados para el análisis in situ del agua, fueron proporcionados por el área de medio ambiente del hospital de apoyo MINSA/Junín: pH metro, conductímetro, turbímetro, marca Hanna, termómetro ambiental, termómetro para medición de la temperatura del agua y GPS. Para el análisis fisicoquímico y microbiológico de las muestras de agua apoyó el equipo de materiales y análisis químico de la Facultad de Ingeniería Química y el laboratorio de análisis de agua de la Universidad Nacional del Centro del Perú.

El tipo de investigación es descriptivo con enfoque holístico. En el estudio se observó las variables de manera natural, en consecuencia, la investigación se encuentra dentro del diseño de campo no experimental pues no manipula variables. Según la perspectiva temporal se considera evolutivo contemporáneo longitudinal debido a que se obtuvieron información de un evento actual y se recolectaron datos (muestras de agua) sobre las variables en dos momentos para evaluar su relación y el cambio que producen.

Las muestras se recolectaron tanto en época de lluvia como de estiaje en las áreas de influencia. Para las muestras significativas de obtención de información de los contaminantes físicos, químicos y microbiológicos, se ubicaron estaciones de muestreo a unos $500 \mathrm{~m}$ de la desembocadura de las aguas residuales.

\section{EI área de estudio}

A continuación, la descripción de las estaciones de muestreo en el lago Junín (Cuadro 1 y Figura 1).

\section{Recolección de datos}

Se establecieron dos etapas de muestreo, época de lluvia y estiaje, la primera de octubre a diciembre de 2015 y la segunda de mayo a julio de 2016 respectivamente con dos repeticiones de muestreo; asimismo, tres estaciones de muestreo en las áreas de descargas de aguas residuales al lago (ciudades aledañas). En cada estación de muestreo se recolectaron muestras de agua para los análisis físico-químicos y microbiológicos en envases esterilizados y demás procedimientos establecidos en el protocolo del Ministerio de Energía y Minas (MINEM, 2007). En todas las estaciones de muestreo se utilizó un GPS. A continuación, el detalle de la investigación. 
Cuadro 1. Estación de muestreo de aguas del lago.

\begin{tabular}{|c|c|c|}
\hline Estación & Posición geográfica & Descripción \\
\hline E1 & $\begin{array}{c}\text { UTM: } 8773293 \\
\text { Latitud: 18L0377014 } \\
\text { Altitud: } 4089\end{array}$ & $\begin{array}{l}\text { Aguas adentro del lago junto a los totorales frente a la } \\
\text { ciudad de Ondores. }\end{array}$ \\
\hline E2 & $\begin{array}{c}\text { UTM: } 8775021 \\
\text { Latitud: 18L0380360 } \\
\text { Altitud: } 4093\end{array}$ & $\begin{array}{l}\text { Aguas adentro y área desértica en el fondo del lago } \\
\text { frente al río Chacachimpa y ciudad de Junín. }\end{array}$ \\
\hline E3 & $\begin{array}{c}\text { UTM: } 8786883 \\
\text { Latitud: 18L0382935 } \\
\text { Altitud: } 4097\end{array}$ & $\begin{array}{l}\text { Aguas adentro cerca a los totorales frente a la ciudad de } \\
\text { Carhuamayo. }\end{array}$ \\
\hline
\end{tabular}

Recolección de muestras del espejo de aguas del lago en áreas de vertimientos de aguas residuales para determinar el estado actual de los niveles de contaminación fisicoquímico y bacteriológico de las aguas con dos repeticiones por estación de muestreo.

Realización in situ de las medidas de la conductividad eléctrica, $\mathrm{pH}$, turbidez y la temperatura del agua y del medio ambiente. Para el análisis bacteriológico se recolectaron de todas las estaciones en frascos de vidrio de $300 \mathrm{~mL}$ previamente esterilizados y trasladados en refrigeración a $4{ }^{\circ} \mathrm{C}$ hasta el laboratorio para su análisis antes de las $24 \mathrm{~h}$ de su recolección. Asimismo, se realizaron los análisis fisicoquímicos de las muestras de agua del lago.

Se realizaron los análisis fisicoquímicos y bacteriológicos de las muestras de agua de los canales de descarga de las ciudades y del espejo de agua del lago.

Para el análisis bacteriológico se utilizó el método de ensayo 'Colilert/IDEXXQuanti-Tray/2000, número más probable (NMP) para coliformes y E. coli’, referencia 9308-2:1990 de la Organización Internacional de Normalización (ISO). Para los indicadores bioquímicos, se realizó la determinación de la demanda bioquímica de oxígeno $\left(\mathrm{DBO}_{5}\right)$ por 5210-B $\mathrm{ROB}_{5}$ días, oxígeno disuelto $\left(\mathrm{O}_{2}\right)$ por el método electrodo de membranas y la demanda química de oxígeno (DQO) por reflujo cerrado fotométrico.

Para determinar el nivel de calidad de agua, se realizó mediante el Índice de la Fundación Nacional de Saneamiento (INSF) de los Estados Unidos, en las tres estaciones E1, E2 y E3 de muestreo del cuerpo de agua, en las áreas de vertimiento de las aguas residuales del lago. Según Ott (1978), el INSF usa una suma lineal ponderada. El resultado debe ser entre 0 y 100 que representa la calidad de agua excelente. Esto encaja con el concepto público general de valoraciones.

Para el análisis de los datos con las técnicas descritas, se utilizaron el libro de Excel 97-2003 y el programa de SPSS 24. Para la obtención de los estadísticos descriptivos del análisis fisicoquímico y bacteriológico, se utilizó el libro Excel 97-2003, luego se aplicó el Anova paramétricos de una vía o factor con el programa SPSS 24, los datos fisicoquímicos y bacteriológicos obtenidos, previa evaluación de la homogeneidad de varianza con estadístico de Levene. Para la determinación de diferencias significativas, se utilizó $(p<0.05)$ para las épocas de lluvia y estiaje en las áreas de muestreo. Al encontrar diferencias significativas $(p<0.05)$ y determinar comparaciones múltiples en cada época y sector de muestreo se utilizó el test post hoc de Tukey. 


\section{Resultados}

De acuerdo a los estadísticos descriptivos de los análisis fisicoquímicos y bacteriológicos de las aguas del lago en las áreas de vertimiento de aguas residuales, provenientes de las ciudades en estudio y considerando la estación y época de muestreo, se tienen los siguientes resultados. La temperatura del agua del lago en época de lluvia presentó una media de $12.2^{\circ} \mathrm{C}$ en las estaciones 1 y 2 de muestreo, correspondiente a las ciudades de Óndores y Junín. En la estación 3 de Carhuamayo presentó $12.50{ }^{\circ} \mathrm{C}$, mientras que en época de estiaje presentaron una media de $10{ }^{\circ} \mathrm{C}$ en las tres estaciones de muestreo en las aguas del lago correspondiente a las áreas en estudio.

La media de la conductividad del agua del lago en época de lluvia en la estación 1 es de $455 \mu \mathrm{S}$ $\mathrm{cm}^{-1}$ y en estiaje $480 \mu \mathrm{S} \mathrm{cm}^{-1}$ en el área de Óndores, la media en época de lluvia en la estación 2 es $451 \mu \mathrm{S} \mathrm{cm}^{-1}$ y en época de estiaje $475 \mu \mathrm{S} \mathrm{cm} \mathrm{cm}^{-1}$ área de Junín y en la estación 6 en época de lluvia es $514 \mu \mathrm{S} \mathrm{cm}^{-1}$ y estiaje $534 \mu \mathrm{S} \mathrm{cm}^{-1}$. Las medias de las conductividades en época de lluvia son menores con respecto a la época de estiaje. En las tres estaciones de muestreo del cuerpo de agua del lago E1, E2 y E3 las medias de dureza total es 144, 146 y $134 \mathrm{mg} \mathrm{L}^{-1}$ respectivamente en época de lluvia, mientras en época de estiaje las medias son ligeramente superior $(156,169 \mathrm{y}$ $179 \mathrm{mg} \mathrm{L}^{-1}$ ) en las tres estaciones debido a la concentración de carbonatos. Presentó un rango de medias de pH 7.7 a 8.37 en las dos épocas de muestreo.

Según Bussing (2002) por lo general el pH de los ríos varía entre 6.5 y 7.4 y la dureza total de 25 a $70 \mathrm{mg} \mathrm{L}^{-1}$. Los lagos suelen ser más alcalinos, con $\mathrm{pH}$ entre 7 y 8 y dureza total entre 20 y 150 $\mathrm{mg} \mathrm{L}^{-1}$. Las aguas del lago Junín contienen medias en época de lluvia, $\mathrm{pH}$ de 7.7 en la estación de muestreo E1, pH de 8.3 en la estación E2 y de 8.37 en la estación E3. En época de estiaje las medias de los $\mathrm{pH}$ son $8.2 ; 8.21$ y 8.3 para E1, E2 y E3 respectivamente. En general se puede considerar un $\mathrm{pH}$ homogéneo y casi constante pero ligeramente superior al rango de Bussing. En cuanto a la alcalinidad en las estaciones E1, E2 y E3 presentaron en sus medias, ligeras variaciones de periodicidad tanto en lluvia como en estiaje.

Estas variaciones son debidas a las fluctuaciones del $\mathrm{CaCO}_{3}$ de 124 a $134 \mathrm{mg} \mathrm{L}^{-1}$ en época de lluvia y de 146 a $169 \mathrm{mg} \mathrm{L}^{-1}$ en época de estiaje. Además, se observan en los resultados que las medias de los sólidos totales reportados son superiores a la alcalinidad en las tres estaciones del cuerpo de agua del lago, esta superioridad se puede atribuir a que al calcio y magnesio podría estar asociado con los nitratos, cloruros y sulfatos. En cuanto a la acidez, $\mathrm{pH}$ y salinidad de las aguas del lago, contienen medias en época de lluvia, pH 7.7 en la estación de muestreo E1, pH de 8.3 en la estación E2 y de 8.37 en la estación E3. En época de estiaje es ligeramente superior a los pH descritos; en general se puede considerar un $\mathrm{pH}$ homogéneo y casi constante.

Los cloruros $\mathrm{Cl}^{-}$determinados en las muestras de agua, en época de lluvia, muestra mayor concentración en la E1 con una media de $13.01 \mathrm{mg} \mathrm{L}^{-1}$; no obstante, que presentan igualdad en las medias de concentración en las estaciones de E2 y E3 de $10.01 \mathrm{mg} \mathrm{L}^{-1}$, en época de estiaje se incrementa las concentraciones del cloro en las estaciones E1 a 14.05, en E2 a 15.07 y en E3 a $12.41 \mathrm{mg} \mathrm{L}^{-1}$. La concentración de sulfatos $\left(\mathrm{SO}_{4}{ }^{-2}\right)$ en el cuerpo de agua del lago en época de lluvia, tiene una media de $38 \mathrm{mg} \mathrm{L}^{-1}$ en la E1. Esta concentración es menor con respecto a la media $99 \mathrm{mg}$ $\mathrm{L}^{-1}$ en la E2 y $41 \mathrm{mg} \mathrm{L}^{-1}$ en E3. Asimismo, la media en concentración de los sulfatos en época de estiaje se incrementa a $43 \mathrm{mg} \mathrm{L}^{-1}$ en E1, $129 \mathrm{mg} \mathrm{L}^{-1}$ en E2 y $64 \mathrm{mg} \mathrm{L}^{-1}$ en E3. 
Las medias de las concentraciones del oxígeno disuelto (OD) en E2 y E3 en época de estiaje; Asimismo, la media E1 en las épocas de estiaje y lluvia se encuentra por debajo de $5 \mathrm{mg} \mathrm{L}^{-1}$ de los límites permisibles para lagos y lagunas. Los resultados estadísticos descriptivos del análisis bacteriológico del agua, en la cual se encuentran los coliformes expresados en NMP/100 mL en época de lluvia demuestran que las medias de las estaciones E1, E2 y E3 son menores con respecto a las medias de la época de estiaje de las mismas estaciones correspondientes al cuerpo de agua del lago de las áreas correspondiente a Óndores, Junín y Carhuamayo.

\section{Calidad de agua}

Los resultados de la calidad de agua del lago, determinados a partir de los análisis fisicoquímicos y bacteriológicos, efectuados mediante el índice de la Fundación Nacional de Saneamiento (INSF) de los Estados Unidos de América, calificaron al cuerpo de agua de las estaciones de muestreo de Óndores, Junín y Carhuamayo como sigue. El índice NSF del agua en las áreas de vertimiento de aguas residuales de la ciudad de Óndores en época de lluvia es 57.7 de acuerdo a la escala de clasificación, es agua de calidad media; mientras que, en época de estiaje el INSF es de 50 aproximando. Se localizó dentro del rango de 26-50, por lo tanto, el agua es de mala calidad.

El INSF de las aguas del lago en áreas de vertimiento de aguas residuales de la ciudad de Junín en época de lluvia es de 60.32 de acuerdo a la escala de clasificación de calidad de agua, es agua de calidad media. Sin embargo, en la época de estiaje el INSF es de 47.62 se encuentra dentro del rango de 26-50, el agua es de mala calidad. El índice NSF de las aguas del lago en áreas de vertimiento de aguas residuales de la ciudad de Carhuamayo en época de lluvia es de $60.06 \mathrm{mg} \mathrm{L}$ de acuerdo a la escala de clasificación, es agua de calidad media; sin embargo, en época de estiaje el índice NSF es de 48.6 mg L se encuentra dentro del rango de 26-50, el agua es de mala calidad.

El Cuadro 2, prueba los resultados del Anova de análisis fisicoquímico y bacteriológico de agua del lago muestreados en las tres ciudades, teniendo en cuenta la época y estación de muestreo. Según la época de muestreo $83 \%$ de indicadores muestran diferencias significativas $(p<.05)$. No obstante, según estación de muestreo en época de lluvia, los indicadores que muestran diferencias significativas son los fosfatos, demanda bioquímica de oxígeno y coliformes totales. Mientras que, en las estaciones muestreados en época de estiaje los indicadores que presentan diferencias significativas son la demanda bioquímica de oxígeno y coliformes totales.

Cuadro 2. Anova del análisis fisicoquímico y bacteriológico de agua del lago Junín.

\begin{tabular}{|c|c|c|c|c|c|c|c|c|c|}
\hline \multirow{2}{*}{$\begin{array}{l}\text { Análisis } \\
(p<0.05)\end{array}$} & \multicolumn{3}{|c|}{ Época de muestreo } & \multicolumn{3}{|c|}{ Estación A, lluvia } & \multicolumn{3}{|c|}{ Estación B, estiaje } \\
\hline & $\mathrm{F}$ & $p$ & Sig & $\mathrm{F}$ & $p$ & Sig & $\mathrm{F}$ & $p$ & Sig \\
\hline Cloruros & 10668 & 0.017 & $*$ & 1754 & 0.313 & ns & 3.319 & 0.174 & ns \\
\hline Fosfatos & 3998 & 0.093 & ns & 24185 & 0.014 & $*$ & 0.141 & 0.874 & ns \\
\hline Solidos totales & 8344 & 0.028 & $*$ & 0186 & 0.839 & ns & 0.671 & 0.74 & $\mathrm{~ns}$ \\
\hline Oxígeno disuelto & 18618 & 0.005 & $*$ & 2468 & 0.232 & ns & 0.044 & 0.958 & ns \\
\hline $\mathrm{DBO}_{5}$ & 22803 & 0.003 & $*$ & 110311 & 0.002 & $*$ & 43.756 & 0.006 & $*$ \\
\hline Coliformes totales & 417872 & 0 & $*$ & 22102 & 0.016 & $*$ & 24.026 & 0.014 & $*$ \\
\hline
\end{tabular}

$\mathrm{A}=$ estaciones de muestreo sectores Óndores, Junín y Carhuamayo en época de lluvia; B= estaciones de muestreo sectores Óndores, Junín y Carhuamayo en época de estiaje; $p$-valor (sig). $\mathrm{F}=$ valor estadístico de contraste. 
De acuerdo a la prueba estadística del Cuadro 3, la diferencia estadísticamente significativa $(p<$ 0.05) entre época de muestreo; la turbidez y el oxígeno disuelto muestran mayor diferencia significativa en la época de lluvia con respecto a la época de estiaje. En cambio, cloruros, solidos totales, demanda bioquímica de oxígeno y coliformes totales muestran mayor diferencia significativa en la época de estiaje con respecto a la época de lluvia.

Cuadro 3. Comparaciones múltiples HSD Tukey de agua del lago.

\begin{tabular}{|c|c|c|c|c|c|c|c|c|}
\hline \multirow{2}{*}{$(p<0.05)$} & \multicolumn{2}{|c|}{ Época de muestreo } & \multicolumn{3}{|c|}{ Estación A, lluvia } & \multicolumn{3}{|c|}{ Estación B, estiaje } \\
\hline & Lluvia & Estiaje & (I) & (J) & Sig & (I) & (J) & Sig \\
\hline Cloruros & $11.01 \pm 2.1 \mathrm{~b}$ & $13.84 \pm 1.5 \mathrm{a}$ & & & & & & \\
\hline Fosfatos & & & Ond & Jun & 0.013 & & & \\
\hline & & & Ond & Car & 0.042 & & & \\
\hline Solidos totales & $665.55 \pm 138 b$ & $879.62 \pm 64 a$ & & & & & & \\
\hline Oxígeno disuelto & $5.81 \pm 1.2 \mathrm{a}$ & $3.49 \pm 0.7 \mathrm{~b}$ & & & & & & \\
\hline $\mathrm{DBO}_{5}$ & $22.67 \pm 19 \mathrm{a}$ & $33.37 \pm 20 \mathrm{a}$ & Ond & Jun & 0.002 & Ond & Jun & 0.016 \\
\hline & & & Ond & Car & 0.0 & Ond & Car & 0.006 \\
\hline Coliformes totales & $3.73 \pm 2.4 \mathrm{~b}$ & $46.63 \pm 16 \mathrm{a}$ & Jun & Car & 0.014 & Ond & Jun & 0.013 \\
\hline & & & & & & Ond & Car & 0.048 \\
\hline
\end{tabular}

$(I)=$ estación de muestreo; $(J)=$ estación de muestreo; $A=$ estaciones de muestreo en Óndores, Junín y Carhuamayo en época de lluvia; $\mathrm{B}=$ estaciones de muestreo en Óndores, Junín y Carhuamayo en época de estiaje.

Según estación de muestreo en los sectores de las 3 ciudades, en época de lluvia para los fosfatos pares con mayor variación presentan el sector Óndores-sector Junín y sector Óndores-sector Carhuamayo; para la DBO5 los pares que muestran mayor variación fueron sector Óndores-sector Junín y sector Óndores-sector Carhuamayo y para los coliformes totales el par de mayor variación muestra el sector Junín-sector Carhuamayo.

\section{Discusión}

A continuación, la determinación del estado actual de los niveles de contaminación físico, químico y bacteriológico de las aguas del lago Junín.

\section{Análisis fisicoquímico de agua del lago}

La dureza total de las aguas del lago es la suma de las concentraciones de calcio y magnesio, ambos expresados como carbonato de calcio, en miligramos por litro. Agua de dureza inferior a $60 \mathrm{mg} \mathrm{L}$ de $\mathrm{CaCO}_{3}$ se considera blanda, si la dureza es superior a $270 \mathrm{mg} \mathrm{L}^{-1} \mathrm{de} \mathrm{CaCO}_{3}$, el agua se considera dura. De acuerdo a los resultados la dureza del cuerpo de agua del lago Junín es superior a la determinación de Bussing (2002) en lagos diferentes, además el resultado del estudio es menor que $270 \mathrm{mg} \mathrm{L}^{-1}$ de $\mathrm{CaCO}_{3}$.

El cloro, presente en el agua residual reacciona con diversos compuestos orgánicos para formar productos clorados cuyos compuestos clorados al no ser separados debidamente en los tratamientos de aguas residuales (caso de las pozas de oxidación de las 3 ciudades), se convierten en cloros residuales que son vertidos al cuerpo de agua del lago Junín. Ello provoca toxicidad sobre los 
organismos acuáticos del lago entre ellos los bentónicos, el pez 'challhua' (Orestias spp.) y algas. Para Nemerow (1998), casi todas las sales, algunas incluso en bajas concentraciones, son tóxicas para ciertas formas de vida acuática. Así, se sabe que los cloruros son tóxicos para peces de agua dulce en concentraciones de 4000 ppm.

El ion de sulfato $\left(\mathrm{SO}_{4}{ }^{-2}\right)$ es muy soluble en agua. Según APHA-AWWA-AWWA CF (1992). El sulfato disuelto puede ser reducido a sulfito y volatilizado a la atmósfera como $\mathrm{H}_{2} \mathrm{~S}$, precipitado como sales insolubles o incorporado a organismos vivos. En contraste, los sulfatos de bario, estroncio y plomo son insolubles en agua y si son vertidos al cuerpo de agua, puede acumularse a través del tiempo produciendo contaminación. Sin embargo, los sulfatos sirven como fuente de oxígeno a las bacterias, en condiciones anaeróbicas, convirtiéndose en sulfuro de hidrógeno.

En este estudio se reportó una concentración media de sulfato de $129 \mathrm{mg} \mathrm{L}$ en sector de Junín en época de estiaje. Hay concentración de fosfatos $\mathrm{PO}_{4}{ }^{-3}\left(\mathrm{mg} \mathrm{L}^{-1}\right)$ en las estaciones de muestreo del cuerpo de agua del lago Junín (Cuadro 2). En el periodo de lluvia como en el periodo de estiaje superan la concentración de $0.4 \mathrm{mg} \mathrm{L}^{-1} \mathrm{PO}_{4}{ }^{-3}$ de los límites permisibles para lagos y lagunas. En efecto, es un peligro la toxicidad para la vida acuática del lago. En este estudio se reportó una media de $21.07 \mathrm{mg} \mathrm{L}^{-1}$ en el sector de Óndores en época de lluvia.

\section{Análisis bioquímico de agua del lago}

La demanda bioquímica de oxígeno en cinco días ( $\mathrm{DBO}_{5}$ ), el cual representa la cantidad de oxígeno necesaria para estabilizar biológicamente la materia orgánica contenida en una muestra de agua. De acuerdo a Barba (2002) 'la DBO, es un estimativo de la cantidad de oxígeno requerido para estabilizar los materiales orgánicos biodegradables por una población heterogénea de microorganismos'. En tal sentido, las concentraciones de $\mathrm{DBO}_{5}$ en todas las estaciones de muestreo del lago Junín, tanto en época de lluvia como en estiaje no se encuentran dentro los límites permisibles para lagos y lagunas.

\section{Análisis bacteriológico de agua del lago}

En cuanto a los coliformes totales presentes en el cuerpo de agua del lago, está de acuerdo con la teoría de Romero (2008) 'el grupo de coliformes totales, grupo coli-aerogenes, incluye los géneros escherichia y aerobacter. En general, se considera el género eschirichia, especie E. coli, como la población de bacterias coliformes más representativa de contaminación fecal'. En tal sentido, los resultados del análisis bacteriológico del cuerpo de agua del lago, en época de lluvia son menores a la época de estiaje de las tres ciudades.

Hecho que debe hacer reflexionar a los actores y externalidades para revertir esta dificultad de contaminación acuática. Urge aplicar estrategias más amigables con el medio ambiente del lago, a fin de conservar el habitad de la flora y fauna endémica.

\section{Determinación del nivel de calidad de agua del lago}

Aguirre et al. (2016) en su trabajo sobre aplicación del índice de calidad de agua (ICA), mencionan el caso del lago Izabal donde los estudios arrojan que la calidad de agua tanto en época seca como lluviosa es categorizada como buena. Mientras que la calidad de agua del lago Junín, determinado 
a partir de los análisis fisicoquímicos y bacteriológicos, efectuados mediante el índice de la Fundación Nacional de Saneamiento (INSF) de Estados Unidos de América, calificaron al cuerpo de agua de las estaciones de muestreo de Óndores, Junín y Carhuamayo como agua de calidad media con promedios de ICA-NSF de 57.7, 60.32 y 60.06 respectivamente para la época de lluvia.

Los promedios de índices para el cuerpo de agua de las tres estaciones fueron de 50.24, 47.62 y 48.6 para la época de estiaje calificado como agua de calidad mala. Índices que difiere a la calidad de agua del río Cunas reportado por Custodio (2013) en la cual '(...) los INSF calificaron a las masas de agua del sector San Blas como agua de calidad buena con ICA-NSF 76.91 para época de lluvia y 72.40 para estiaje'. Mientras que para los sectores de 'Huarisca' y 'La Perla' este índice calificó a las masas de agua como agua de calidad media. La diferencia de la calidad de agua se debe a factores de presiones antropogénicas a las que están expuestas cada sistema acuático, tanto en sectores de masa de agua como en época de muestreo.

Se percibe que el lago cada vez más está contaminado con los residuos de los pasivos de las empresas mineras del río San Juan que traslada materias inorgánicas (zinc, plomo, cobre, entre otros) hasta $50 \%$ de las áreas del espejo de agua para luego precipitarse hacia el fondo del lago obstruyendo el desplazamiento de los organismos y los rayos de luz del agua necesarios para la subsistencia de todo ser vivo (zooplacton y fitoplacton). Hecho, que encamina al lago a la colmatación. Asimismo, al ser depositadas materias orgánicas y ácidos a través de las aguas residuales de las ciudades circundantes, está disminuyendo su capacidad de autorregulación y el sustento para la vida acuática.

Ocasionan la formación de fases inmiscibles por presencia de disolventes orgánicos, grasas y aceites. El cloro del agua residual al reaccionar con diversos compuestos orgánicos forma productos clorados que son vertidos al cuerpo de agua del lago, provocando toxicidad sobre los organismos acuáticos especialmente peces. Factor importante a las intoxicaciones producidas por el cobre y zinc causantes de la disminución de la 'challhua' (Orestias spp.), principal alimento del ave endémico zambullidor de Junín (Podiceps taczanowskii). Los detergentes son responsables de la presencia de los fosfatos en las aguas residuales.

Al ser descargados al cuerpo de agua, generan el rápido crecimiento de algas. Éstas, utilizan gran cantidad de oxígeno en su crecimiento y desarrollo, ocasionando déficit de oxígeno para la biota acuática en consecuencia la muerte de animales. Según Doménech (2014), en el agua 'el contaminante puede desplazarse a capas más profundas ayudándose de movimientos advectivos de las masas de agua y antes de ser eliminado por biodegradación, puede incorporarse a organismos vivos por bioacumulación o bien retornar a la atmósfera por volatilización'. En este escenario, se percibe que los animales son los más afectados debido a que estos manifiestan malestares, sintomatología o comportamientos atípicos.

Los comuneros lo perciben como consecuencia de la contaminación de su lago. Se observa que el mayor cambio percibido en el presente siglo es la amenaza de extinción de la gallineta negra (Laterallus tuerosii), la rana gigante (Batrachophrynus macrostomus) y el zambullidor de Junín (podiceps taczanowskii). Anterior a la depredación, los campesinos dan cuenta que antes de la construcción de la represa Upamayo (1927), la instalación de las empresas mineras (1960) y el crecimiento poblacional en el presente siglo, el lago tenía una profundidad de $15 \mathrm{~m}$ en promedio. 
Era navegable utilizando caballito de totora como medio de trasporte ribereño. Además, era el principal sustento de alimentación de la población en forma organizada, ya que existían asociaciones de pescadores y cazadores de rana y cuy silvestre (Cavia tschudii). Asimismo, fuente de recursos vegetales como la totora y en las zonas de amortiguamiento existían pastos naturales o pajonales exenta de contaminación que se convertían en alimento principal de vacunos y ovinos. Se utilizaban las 'champas' (pastos de fibra gruesa) como fuente de energía para cocción de alimentos por costumbre ancestral.

Del Sante (2011) concluye que 54\% de los encuestados considera que el lago Junín ya no presenta la misma calidad y cantidad de agua, de este grupo, $76 \%$ notó o escuchó de cambios en el lago Junín en los últimos 30 años. De este último grupo, 39\% considera que la desaparición de la rana Junín es el mayor cambio de las últimas tres décadas, mientras $28 \%$ considera que existe mayor contaminación. Otro factor contaminante del ecosistema acuático del lago Junín en el aspecto bacteriológico es la presencia de coliformes totales, específicamente el género eschirichia, especie E. coli, considerado como la población de bacterias coliformes más representativa de contaminación fecal.

Al respecto Hidalgo y Mejía (2010) mencionan que 'el problema principal identificado es la contaminación por aguas residuales domésticas (coliformes totales)'. Para remediar el problema pueden realizar controles bacteriológicos por la Dirección General de Salud (DIGESA) y la Comisión del 'Plan Chinchaycocha'. Empero, no se programan acciones mitigadoras de contaminación bacteriológica. El índice NSF de las aguas del lago en las áreas de vertimiento de aguas residuales de la ciudad de Óndores en época de lluvia es de 57.7 de acuerdo a la escala de clasificación de calidad de agua, siendo agua de calidad media. Sin embargo, en época de estiaje el INSF es de 50 aproximando, se encuentra dentro del rango de 26-50, por lo tanto, el agua es de calidad mala.

El INSF de las aguas del lago en áreas de vertimiento de aguas residuales de la ciudad de Junín en época de lluvia es de 60.32 de acuerdo con la escala de clasificación de calidad de agua, es considerada agua de calidad media. Sin embargo, en la época de estiaje el INSF es de 47.62 se encuentra dentro del rango de 26-50, se infiere que el agua es de mala calidad.

El índice NSF de las aguas del lago en áreas de vertimiento de aguas residuales de la ciudad de Carhuamayo en época de lluvia es de $60.06 \mathrm{~m} \mathrm{~L}^{-1}$ de acuerdo a la escala de clasificación, es agua de calidad media. Sin embargo, en época de estiaje el índice NSF es de $48.6 \mathrm{mg} \mathrm{L}^{-1}$ se encuentra dentro del rango de 26-50, entonces el agua es de mala calidad.

A pesar de la amenaza de extinción, se ubicaron algunos ejemplares en edad de renacuajos a kilómetros de distancia del lago en el afluente rio Chacachimpa en el sector del 'Santuario de Chacamarca'. Según la expedición conformada, por la Universidad Continental de Huancayo, el Cuerpo de Paz Norteamericano, el Servicio Nacional de Áreas Protegidas (Sernap) y la comunidad San Francisco de Chichausiri, informan que la rana gigante de Junín no está extinta: hallaron renacuajos, empero, todo indica que sigue en riesgo de extinción (Diario 'La República', 2016). 


\section{Conclusiones}

Efectivamente, el lago Junín presenta evidencias de polución. Los componentes indican niveles de contaminación fisicoquímico de las aguas en las áreas de vertimientos de aguas residuales, según las estaciones y época de muestreo. Superan los estándares de calidad ambiental para agua de lago y lagunas. a. Las concentraciones de fosfatos PO4-3 (mg L $\left.\mathrm{m}^{-1}\right)$ en el cuerpo de agua del lago, en los periodos de lluvia y estiaje superan los límites permisibles para lagos y lagunas, siendo un peligro de toxicidad para la vida acuática; y b. La concentración de oxígeno disuelto (OD) más bajas en época de estiaje presentaron las estaciones de Junín con media $3.42 \mathrm{mg} \mathrm{L}^{-1}$ y la estación de Óndores con media $3.41 \mathrm{mg} \mathrm{L}^{-1}$.

De acuerdo con los resultados bacteriológicos la concentración de coliformes termotolerantes en período de lluvia son menores con respecto al periodo de estiaje del cuerpo de agua del lago. Este comportamiento permite afirmar que no existe tratamiento de las aguas residuales de las ciudades circundantes; por tanto, existe el peligro de modificación del ecosistema del lago con impactos impredecibles en la biodiversidad acuática.

Las aguas del lago en las áreas de vertimiento de aguas residuales de la ciudad de Óndores con valor de ICA-NSF 50, ciudad de Junín con ICA-NSF 47,62 y ciudad de Carhuamayo con ICANSF de 48.6, en la época de estiaje son aguas que están consideradas en el nivel de mala calidad.

La descompensación ecológica se traduce en daños para la biodiversidad del lago, el cual evidencia animales en peligro de extinción, como la rana gigante, el zambullidor de Junín y la gallareta negra.

Las descargas de aguas residuales es un factor contaminante con peligro de toxicidad para la vida acuática del lago. Se alerta la necesidad impostergable de mitigar la problemática, sugiriendo generar políticas ambientales que identifiquen, planeen, implanten y evalúen los procesos e impactos de las instituciones periféricas al lago Junín.

\section{Literatura citada}

Agudelo, R. 2005. El agua, recurso estratégico del siglo XXI. Rev. Facultad Nacional Salud Pública. 23(1):91-102.

Aguirre, M.; Vanegas, E. y García, N. 2016. Aplicación del índice de calidad de agua (ICA). Caso de estudio: Lago Izabal, Guatemala. Rev. Cienc. Téc. Agrop. 25(2):39-43.

Alarcón, B. y Ñique, M. 2016. Índice de calidad de agua según NSF del humedal laguna 'Los Milagros' (Tingo María-Perú). Universidad Nacional La Agraria de la selva. Revista Indes. 2(2):98-107.

Apha-Awwa-Wpcf. 1992. Métodos normalizados para el análisis de aguas potables y residuales. Madrid, España. 1-45, 4-30, 9-137. pp.

Autoridad Administrativa del Agua Mantaro. 2017. Plan de manejo ambiental sostenible Chinchaycocha 2017-2021. Perú. 19 p.

Barba, L. 2002. Conceptos básicos de la contaminación del agua y parámetros de medición. Santiago de Cali, Colombia. $26 \mathrm{p}$. 
Bussing, W. 2002. Peces de las aguas continentales de Costa Rica. Freswater fishes of Costa Rica. Editorial de la Universidad de Costa Rica, San José de Costa Rica. 15 p.

Carrera, W. 2011. Influencia del vertido del efluente líquido de la compañía minera AUREX, SA en el ecosistema acuático del río 'San Juan'. Tesis de pregrado. Universidad Nacional Daniel Alcides Carrión. Cerro de Pasco, Perú. 81- 88 pp.

Carrillo. A. y Villalobos, R. 2011. Análisis comparativo de los índices de calidad de agua (ICA) de los ríos Tecolutla y Cazones en el periodo marzo-diciembre 2010. Tesis de pre grado. Universidad Veracruzana. Poza rica-Tuxpam. 5 p.

Chamorro, A. y Medrano, R. 2010. Plan de manejo con fines de conservación de las especies de aves amenazadas del lago Chinchaycocha: Zambullidor de Junín (Podiceps taczanowskii), Gallinetita de Junín (Laterallus tuerosii) y Parihuana (Phoenicopterus chilensis), en el ámbito de la reserva nacional de Junín. Perú. 28-41 pp.

Custodio, M. 2013. Análisis de la biodiversidad de macroinvertebrados bentónicos del río cunas mediante indicadores ambientales. Tesis de doctorado. Universidad Nacional del Centro del Perú. Huancayo, Perú. 90 p.

Custodio, M. y Chávez, E. 2017. Evaluación del estado trófico del río Cunas mediante índices físicos, químicos y biológicos, en dos periodos climáticos-Junín, Perú. Ambiente. 1(2):36-36.

Del Sante, S. 2011. Estudio de la percepción ambiental de los pobladores de la comunidad de 'San Juan' de Óndores acerca de los contaminantes vertidos en el lago Junín. Tesis de pregrado. Universidad Nacional Agraria la Molina. Lima, Perú. 146 p.

Diario 'La República'. 2016. La rana gigante de Junín no está extinta. https://larepublica.pe/sociedad/779274-junin-hallan-ranas-de-mas-de-medio-metro-delargo. 22 de junio.

Doménech, X. 2014. Fundamentos de química ambiental. Madrid, España. II. 196-218 pp.

Español, I. 2016. Evaluación del impacto ambiental. Fundamentos. Madrid, España. Editorial Dextra. 139 p.

Flusche, M.; Geoffrey, S.; Donald, R.; Donald, S. and Scott, S. 2005. Constraining water sources and hydrologic processes from the isotopic analysis of water and dissolved strontium, Lake Junín, Perú. J. Hydrol. 312(1):1-13. doi: 10.1016/j.jhydrol.2005.02.021

Hidalgo, M. y Mejía, E. 2010. Diagnóstico de la contaminación por aguas residuales domésticas, cuenca baja de la quebrada 'La Macana', San Antonio de Prado. Medellín, Colombia. 2 p.

INRENA. 2000. Instituto Nacional de Recursos Naturales. Plan Maestro de Reserva Nacional de Junín. Ministerio de Agricultura. Perú. 11-13 pp.

Manahan, S. 2007. Introducción a la química ambiental. Universidad Nacional Autónoma de México (UNAM), México, DF. 164 p.

Marcelo, A. 2018. Evaluación de los factores fisco-químicos del agua del lago Chinchaycocha, Pasco-Junín. Universidad Nacional Federico Villareal, Lima, Perú. 104 p.

MINAM. 2015. Ministerio del Ambiente. Informe técnico Núm. 354-2015 del Ministerio del Ambiente. Matriz de evaluación del plan de manejo ambiental sostenible Chinchaycocha 2012 -2016. Lima, Perú.

MINEM. 2007. Ministerio de Energía y Minas. Protocolo de monitoreo de calidad sanitaria de los recursos hídricos superficiales. Lima, Perú. 1-34 pp.

Naquira, C. 2010. Las zoonosis parasitarias: problema de salud pública en el Perú. Rev. Peruana Med. Exp. Salud Púb. 27(4):494-97. http://www.scielo.org.pe/pdf/rins/v27n4/ a01v27n4.pdf. 
Nemerow, N. 1998. Tratamiento de vertidos industriales y peligrosos. Ingeniería medioambiental. Madrid, España. 4 p.

Ott, W. 1978. Environmental Indices, theory and practice, AA Sciencie, Ann Arbor, Michigan, USA. $371 \mathrm{p}$.

Plan Maestro-RNJ. 2012. Reserva Nacional de Junín. Plan maestro 2008-2012. Pasco-Junín, Perú. 86-98 pp.

Romero, J. 2008. Lagunas de estabilización de aguas residuales. Colombia. 39 p.

Soni, H. B. and Thomas, S. 2014. Assessment of surface water quality in relation to wáter quality index of tropical lentic environment, Central Gujarat, India. Inter. J. Environ. 3(1):168-176.

TCN. 2013. Trabajos de Ciencias Naturales. Contaminación de lagos y otros humedales. http://g10naturales1e.blogspot.pe/. 